\title{
Personal determinants of style features of pedagogical interaction as a factor of successful professional activity of the teacher
}

\author{
Larisa Ogannisyan*, Sergey Kotov, Marina Akopyan and Yury Borzilov
}

South Federal University, Department of Development Psychology, 344006 Rostov-onDon, Russia

\begin{abstract}
This study focuses on the problem of relationships between personality traits and stylistic characteristics of professional interaction between a teacher and student, the consideration of personal determinant of the stylistic peculiarities of their interaction, as well as the styles of professional activity of a teacher. The model of interaction of subjects of educational process, from the point of view of innovative personalityoriented education is considered. And the result of this interaction is the transformation of educational features into personal and the transition to personal meanings. It is the personal importance of the subject of interaction and the interaction itself that contributes to the formation of the subjective position of the student and the teacher. The main emphasis is placed on the subject-subject interaction of participants of the educational process, personal determinants of style features of psychological and pedagogical interaction, which contribute to the development of the success of professional activity of the teacher.
\end{abstract}

The relevance of this study is due to the growing interest in the profession of teacher and the lack of experimental research on the influence of the style of pedagogical interaction on the success of independent activity of students. In connection with modern processes of particular importance is the project activity as a style of interaction of the teacher with students, which aims to improve the quality of education, its personal efficiency and productivity in interpersonal contacts.

The interdisciplinary nature of the problem of the relationship of personality and style characteristics of professional interaction of the teacher determines the complexity of establishing the scientific basis for the study of this phenomenon. The analysis of pedagogical and psychological literature shows that, despite the diversity and breadth of pedagogical and psychological research on the conceptualization of the concept of "style", the allocation and description of different styles of activity and the factors determining them, the relationship of style and efficiency (A. Adler, G. Allport, K. Levin, V. S. Merlin, E. A. Klimov, E. P. Ilyin et al.) relatively little study remains the area of the relationship of personality and styles of professional activity of the teacher. At the same time, it is the personality of the teacher and the student that plays an important role in determining the educational process, in choosing ways to establish and maintain contact in the process of

\footnotetext{
${ }^{*}$ Corresponding author: laogannisyan@sfedu.ru
} 
independent activity. Therefore, it is important to study the personal determinants of style features of teacher-student interaction. The presence of their own style of activity is a kind of indicator of the formation of professional identity of the teacher.

To solve the tasks, we have used theoretical: analysis and synthesis, modeling and empirical, including pedagogical experiment, analysis of the results of students and teachers and problem presentation. And also, the methods of individual creative approach characterized by high creative potential were applied, forcing the teacher to direct thinking on constant search of meanings of various methods, opportunities of practical application in activity. Knowledge of methods contributes to the emancipation of the teacher, provides the basis for the implementation of creativity, initiative, creativity, increasing the efficiency of personal determinant of the stylistic peculiarities of pedagogical interaction of the teacher and the student.

The stylistic aspects of the teacher's interaction are constantly in the focus of attention of both the teacher and the student, regardless of belonging to different schools and areas of professional activity. However, there is no clear understanding of what is the style of interaction of the teacher on the formation of the success of independent activity of students in the educational process, as well as the factors that determine the formation of this style.

The problem of style characteristics of professional interaction of the teacher has an interdisciplinary character: the personality of the teacher as the subject of the educational process, its features, manifested in professional activity, are the subject of consideration of pedagogy and psychology of personality; the nature of the educational process and its conditionality style features of professional interaction of the teacher and the student is an area of interest of age and social pedagogy and psychology. However, practice shows that the lack of reflection on the style features of professional pedagogical interaction does not allow the teacher to effectively build their work [1]. Awareness of the specialist's own style of interaction will allow him to productively use the resources of his personality in teaching practice.

Features of the style of interaction as an object of study is its ambiguity and diversity. There is also a need to find conceptual grounds for considering the problem of interrelation between the style of interpersonal interaction and other aspects of personality manifestation, including its individual characteristics.

The problem of ambiguity of the term "style" is caused by the use of similar concepts in the literature: type, strategy, method, which creates significant difficulties in the analysis of existing classifications of styles. As a rule, the interdisciplinary concept of "style" is used when they want to emphasize how this phenomenon differs from other similar phenomena and what is its uniqueness. Thus, "style" - a concept inherently differentiating similar phenomena, while the type is a kind of set of features. Over time, style becomes the subject of consideration of modern psychology, where the concept of "style", or "individual style", is used in different contexts: "cognitive style", "style of interaction", "leadership style", "communication style", "style of activity", as well as "style of professional activity", which corresponds to the main directions of research style [2].

The process of interaction is accompanied by interpersonal relationships that reflect the personal orientation of the subject" [3].

Thus, we define interaction as a joint activity of two subjects, which is mediated by communication and is determined by the General nature of their relations, and in the process of interaction there is a common material object that mediates activity (figure 1).

The model of inter-object interaction, shown in figure 1, presents an integrated approach to understanding this phenomenon, namely: the main purpose of the interaction is to create a common result, which is achieved through interaction with the object. Meanwhile, the means of interaction is communication, which is a projection of the relationship of subjects [4]. 


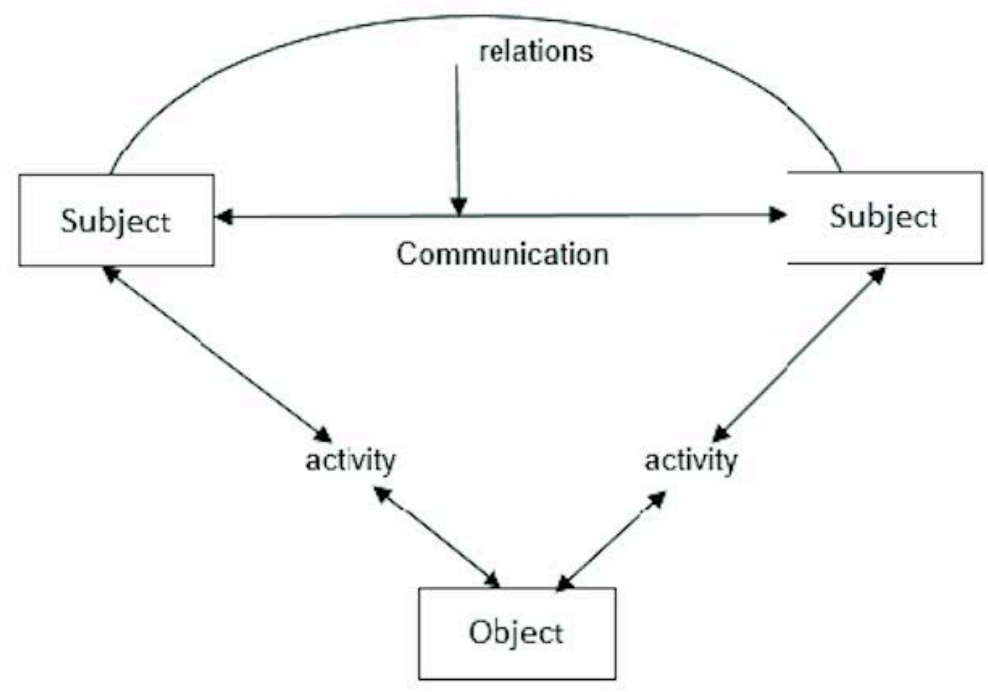

Fig. 1. The model of subject's interaction

Taking into account the integrated nature of the interaction of subjects as a social phenomenon, we characterize pedagogical interaction as a special case of inter-subject interaction. It should be agreed that the interaction involves partnerships, and the impact involves alternately staying in the object position, which is contrary to the subject-activity approach, and, consequently, the methodological principles of our study. We consider the idea of cooperation to be decisive in the study of pedagogical interaction.

If we talk about the origins of the relationships of subjects of educational process, they can be found in the ideas of the enlightenment of the Renaissance (I. Herbart, Diesterweg, F., J. Comenius, J. Locke, Th. Pestalozzi, J.-J. Rousseau, etc.), who noted the humanistic relationship of the teacher and the student on the basis of subject-subject communication. The study A. Kirichuk suggested that pedagogical interaction combines education (transfer of values as the content of pedagogical work) and communication (form of organization of the pedagogical process). In the process of cooperation subject-object relations are transformed into subject-subject.

Thus, cooperation is a means of forming the subjectivity of participants and at the same time a form of subject-subject interaction. This idea is confirmed in the studies of $\mathrm{V}$. Gorshkova, N. Sedova, G. Shchukina, which indicate that the joint activity is a specific form of subject-subject interaction. Therefore, the definition of pedagogical interaction is based on the following provisions: interaction has dialectical character; interaction has integrative character; the level of pedagogical interaction is a measure of manifestation of subjectivity of its participants.

The common object of interpersonal interaction is reasoning, which depends on the course of communication events and determines the nature of the subjects ' activities. According to the theory, L. Velitchenko, the General object of educational interaction is the educational text (text of the textbook, thematic broadcasting of the teacher, focused on perceptual capabilities of students).

Scientists presented the structure of pedagogical interaction in different ways. If you try to generalize all the views, it is possible among its components, except for these components, to identify ways of learning - Socratic (M. Novikov), erotematic (P. 
Yurkevich), heuristic (P. Kapterev); activity of the student (M. Novikov, K. Ushinsky, P. Kapterev); qualities of the teacher (F. Yankovich, H. Chebotarev, N. Bunakov).

Given these provisions, the model of pedagogical interaction can be represented as follows: in the model (figure 2) the learning process is presented as an exchange of cultural and educational meanings between the subject of learning and the subject of teaching. The cultural environment and the subject of learning as a carrier of cultural meanings form a field in which the formation of the subjective position of the subjects of learning through the acquisition of personal meanings in the process of interaction. Reasoning in a simplified scheme looks like a set of texts and various activities, and a means of communication, as a basic component of interaction, is a dialogue. The result of such interaction is the transformation of cultural meanings into educational and their interiorization, i.e. the appearance of personal meanings. In turn, it is the personal importance of the subject of interaction and the interaction itself that contributes to the formation of the subjective position of the student and the teacher.

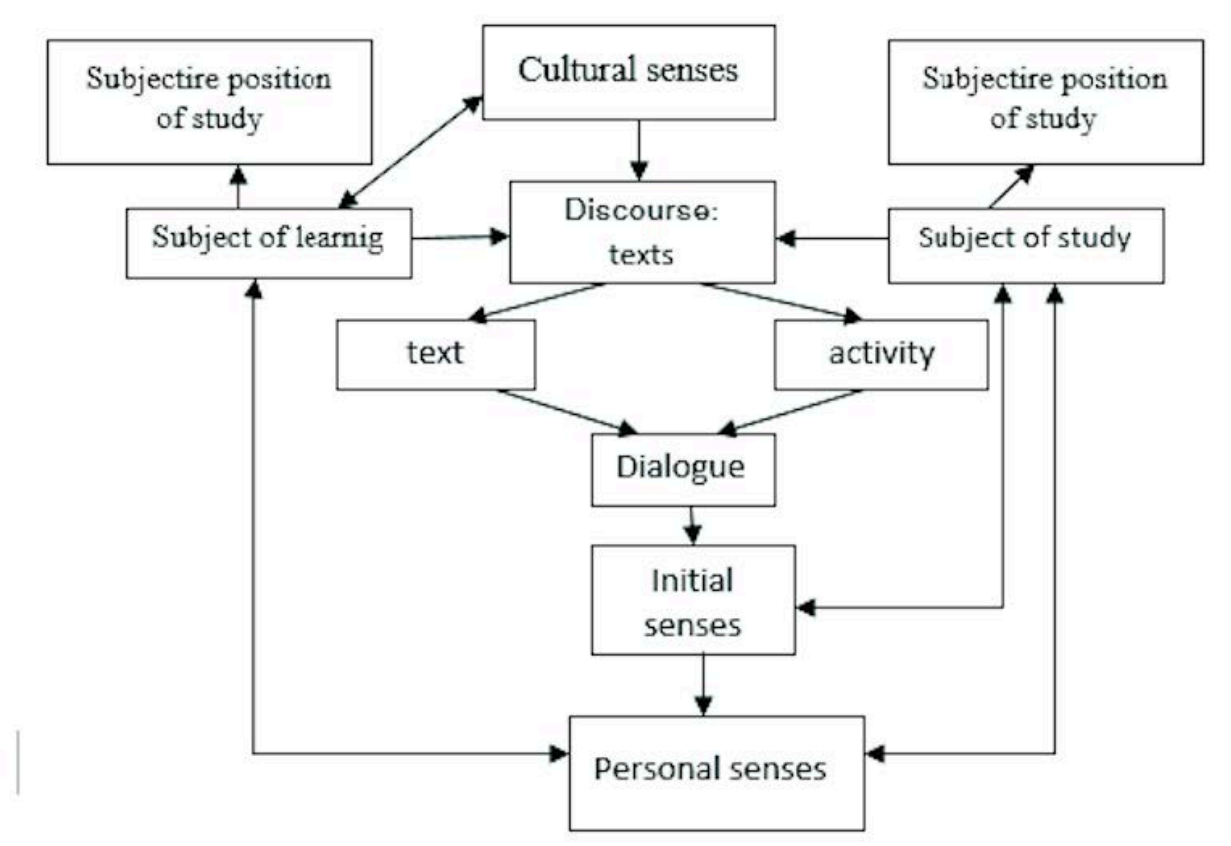

Fig. 2. The model of pedagogical interaction

There are different classifications of interaction types, which are based on the hierarchical principle of construction. On the basis of the given classifications the forms of interaction between the participants of the learning process are determined, depending on the level of subjectivity of teachers and students and their relations: Autonomous action, influence, support, cooperation. Let us present their characteristic [5]. Autonomous action (subject-alienated relations), in fact, is a mutual parallel and simultaneous action, but the subjects do not perceive the effects of each other, so their actions are not interdependent. Pedagogical impact (subject-object relations), as interpreted V. Petukhova, aimed at opening potential possibilities of the student to be the subject. Under the support (polysubject relations) is understood as a way of interaction, providing the creation of optimal conditions for the subject of the development of optimal decisions in different situations of life choices. And the subject of development can be both a person and a 
system. Cooperation (subject-subject, activity-mediated relations) is defined as the most highly organized form of interaction organization. It is cooperation that is responsible for the subject-subject level of interaction, since it is characterized by such features: conscious activity, the ability to goal-setting and reflection, freedom of choice and responsibility for it, uniqueness, certainty in time (M. Kagan, A. Leontiev, S. Rubinstein, etc.). It should also be noted that in the process of subjectivity formation each subsystem goes through 4 stages: Autonomous position, object of interaction, subject of subject-object interaction, subject of subject-subject interaction.

So, at the beginning of training the student is in an alienated relationship with the teacher and the environment of the University, because it is not included in the learning process, is not its subsystem. At the next level - subject-object, the student plays the role of the object. Finally, the highest level, according to our hierarchy, is cooperation, which is characterized by the polysubject nature of relations and the implementation of joint activities [6]. Since the activity of the student at the University involves both teaching and learning (ie. professional activity), then at this level, two degrees are defined - the subject of cooperation and the subject of professional activity. Common objects are in the first case the text in a broad sense - as a field of meaning [7], and in the second, the highest level the real learning process. It is assumed that in the course of their activities the student rethinks it and as a result there is a subject-subject interaction.

Thus, we define two aspects of subject-subject interaction: the first lies in the plane of relations, and the second - in the plane of activity. Such interaction includes communication as the exchange of information, interaction as the exchange of actions and people's perception of each other on its basis.

In front-line training, the teacher manages the educational activities of the entire audience, organizes cooperation, determines the pace of work. The pedagogical value of this form of work is that it provides active activity of each student. The degree of independence of individual work increases as students master educational skills. Group work occurs when the teacher communicates with a group of students who interact both with the teacher and with each other [8]. The most expedient is the acquisition of groups on the principle of combining students of different levels of learning, which provides the most intensive exchange of experience and knowledge between students. Group work is important from an educational point of view, as it teaches students to work in a team.

In conclusion, it should be noted that the consideration of the main aspects of the style of professional activity showed that the person in the context of the determination of its development activity is considered from the position of compliance with the profession and the success of the activity in it. Summarizing the above, we can conclude that the personal determinants of style features of pedagogical interaction contribute to the successful development of professional activity of the teacher.

In the course of experimental work, we have received confirmation that the purposeful work of the University in the educational space of the southern Federal University, associated with ensuring the conditions of interpersonal communication and interaction of teachers and students, really develops certain personal qualities and values, contributes to the development of the success of professional activities of the teacher. We realize that in a short time of the experiment it is impossible to achieve a significant increase in the results, because interpersonal communication is a process in which the value-semantic, sensory, cognitive, behavioral spheres of personal development of the student are involved. Nevertheless, the presented results confirm our hypothesis and the adequacy of the methods of pedagogical research.

In conclusion of this article we can say that the development of personal qualities and style of students and teachers, really contribute to the development of their interpersonal communication and the success of professional activities of the teacher in the pedagogical 
space of the University.

\section{References}

1. V.A. Novgorod, Personal resource of University students as a determinant of effective professional self-determination (Sochi, (2012)

2. V.A. Slastenin, Pedagogical education and science. 5, (2009)

3. M.A. Hakobyan, S.S. Izyumskaya, Problems of modern pedagogical education. 57(6), (2016)

4. I.V. Abakumova, P.N. Ermakov, M.V. Godunov, Psychology in Russia: State of the Art. 11(4), $200-210$ (2018)

5. O.V. Rogach, E.V. Frolova, T.M Ryabova. European Journal of Contemporary Education, 8(2), 338-347 (2019)

6. L.V. Goryunova, S.V. Kotov, M.A. Akopyan, L.A. Ogannisyan, Y.P. Borzilov, Astra Salvensis, 6, (2018)

7. L.A. Ogannisyan, M.A. Akopyan, D.N. Misirov, Y.P. Borzilov, S.V. Semergey The 6th International Conference on Management and Technology in Knowledge, Service, Tourism \& Hospitality (2018)

8. S. Peker, Y. Inand1, F. Gılıç, European Journal of Contemporary Education, 7(1), 150$164(2018)$ 